2018-10

\title{
Soil sterilisation methods for use in OECD 106: How effective are they?
}

\author{
Lees, $\mathrm{K}$
}

http://hdl.handle.net/10026.1/12343

10.1016/j.chemosphere.2018.06.073

Chemosphere

Elsevier

All content in PEARL is protected by copyright law. Author manuscripts are made available in accordance with publisher policies. Please cite only the published version using the details provided on the item record or document. In the absence of an open licence (e.g. Creative Commons), permissions for further reuse of content should be sought from the publisher or author. 
1 This is an open access accepted copy. Available at: Chemosphere, 209, 61-67.

2 doi:10.1016/i.chemosphere.2018.06.073

\section{Soil sterilisation methods for use in OECD 106: How effective are they?}

4 Katherine Lees $^{1}$, Mark Fitzsimons ${ }^{1}$, Jason Snape ${ }^{2}$, Alan Tappin ${ }^{1}$, Sean Comber ${ }^{1 *}$

$5 \quad{ }^{1}$ Biogeochemistry Research Group, Plymouth University, Plymouth, UK.

$6 \quad{ }^{2}$ AstraZeneca UK, Global Safety, Health and Environment. Macclesfield, UK

$7 \quad$ *Corresponding author: sean.comber@plymouth.ac.uk

8 Biogeochemical Research Centre

9 B525 Portland Square, Plymouth University,

10 Drake Circus, Plymouth, PL4 8AA, UK.

11 Tel: +44 (0) 1752585974

12 Abstract

Under many circumstances chemical risk assessments for pharmaceuticals and other substances are required to differentiate between 'loss' of a chemical from the aqueous phase as a result of abiotic (sorption or precipitation reactions) or biotic (biodegradation) processes. To distinguish only abiotic processes, it is necessary to work under sterile conditions. Reported methods include poisoning the soil with sodium azide, irradiation and autoclaving. However, a key aspect of any testing is the representativeness of the matrix and so any sterilisation procedure needs to ensure that the integrity of the sample is maintained, in particular particle size distribution, $\mathrm{pH}$ and organic carbon partitioning potential. A number of controlled laboratory experiments were performed on 3 different types of soil. Results indicated that none of the methods successfully sterilised the soils and some physico-chemical changes in soils were identified post-treatment. Autoclaving destroyed the soil structure, therefore potentially affecting its sorption behaviour and sodium azide changed the $\mathrm{pH}$ of the loam soil solution by $0.53 \mathrm{pH}$ units. Gamma irradiation exhibited least disruption to the tested soils physico-chemical properties. It was therefore concluded that gamma irradiation was the best available method for sterilising soils in preparation for sorption-desorption experiments; however care needs to be taken with this method to ensure that microbial activity is absent, or quantified if present. The changes to soils after sterilisation varied depending on the individual soil properties, indicating that soils should be studied on a case-by-case basis.

Keywords: soil, sterilisation, abiotic, OECD106, pharmaceuticals 


\section{Introduction}

Active pharmaceutical ingredients (APIs) are frequently ionisable compounds; their fate and behaviour is intrinsically controlled by a combination of their physico-chemical properties and those exhibited by the matrix they find themselves in. Depending on the API and the environmental conditions loss from soil pore waters through sorption to soil particles, biodegradation, abiotic degradation (e.g. photodegradation), volatilisation and leaching into groundwater or other water sources are all potential pathways through the environment (ECETOC 2013; Lees et al. 2016). When undertaking environmental risk assessments of chemicals in soil matrices it can be difficult to distinguish the pathways of loss from soil pore waters and ultimate fate of the chemical in the environment. To separate biodegradation from other loss mechanisms, soil must be sterilised by an appropriate chemical or physical method (OECD 2000). The OECD 106 guideline (OECD, 2000), like many other standardised methods, does not define sterilisation or recommend a method to achieve it. The aim of sterilisation is to remove or kill all living microbes (bacteria, fungi, and their spores) and other microorganisms in soils (Oxford University Press 2002). In contrast, other methods have been used which supress microbial activity, and at the same time reduce the biodiversity of the soil fauna, or keep the microbial population stable throughout the length of experiments; these include the addition of sodium azide and mercuric chloride. It should be noted that the use of the term "suppress" does not imply, nor quantify, any acceptable level of sterility. Consequently, it renders uncertain any statements made thereafter regarding abiotic vs biotic chemical behaviour.

When sterilising soils the physico-chemical characteristics must remain unchanged so that the results can be robustly compared with those from non-sterile experiments. For recalcitrant, non-polar compounds the relative importance of some environmental variables is 
of little concern. However, for ionisable compounds, such as many APIs and pesticides, the stability of certain physico-chemical properties of the soil are critical in controlling the fate of the substance and to interpret data obtained from any given experiment. The most important soil variables affecting interactions of soil with ionisable compounds include, $\mathrm{pH}$, dissolved organic carbon (DOC), cation exchange capacity (CEC), clay structure, ionic strength and particle size (Lees et al. 2016). A decision tree showing the pathways for identifying a suitable sterilisation method for an OECD 106 experiment is presented in Figure S1.

The heterogeneity of soil matrices and the presence of particulate material increases the levels of complexity when considering sterilisation compared with aqueous samples where filtration to $<0.2 \mu \mathrm{m}$ is often considered sufficient, or at least practical, to remove bacteria from the sample (Jornitz and Meltzer, 2000) although complete removal is not always achieved (Leuf et al., 2015). The methods of sterilisation which are the subject of this work are those typically used for soil matrices, namely; autoclaving, gamma irradiation and addition of sodium azide. Autoclaving and gamma irradiation have been used to sterilise soils (Al-Rajab et al. 2010; Redshaw et al. 2008; Xu et al. 2009; Zhang et al. 2013) while sodium azide has been used to supress the microbial activity within a soil (Lin and Gan 2011; Zhang et al. 2013). Other sterilisation methods have included dry heat, microwave radiation and other chemical additions such as mercuric chloride or chloroform (Trevors 1996; Wolf et al. 1989). These chemicals were not used in the current study as reports have shown them not to be successful; as well as being dangerous to handle, they have consequently been banned from most applications (Wolf et al. 1989).

Although previous studies have compared sterilisation techniques, these either pre-date the OECD 106 test methodology now used routinely for soil risk assessment (Skipper and 80 Westermann 1973; Wolf et al 1989) or were undertaken on a restricted set of sterilisation methodologies (McNamara et al., 2003). The objectives of this study were, therefore, to 
investigate the efficacy of common methods of soil sterilisation in reducing the microbial population, and how soil structure may be physically influenced by the process that may therefore impact sorption experiments described in the OECD 106 guideline. Two analytical techniques were used to estimate the extent of sterilisation; fluorescein diacetate (FDA) hydrolysis (Adam and Duncan 2001) and counting colony forming units on tryptone-glucoseyeast agar plates (Eaton et al. 1995).

\section{Materials and Methods}

\subsection{Soils}

Characteristics of the soils used for this work are summarised in Table 1. The sandy loam and loam were pre-characterised 'standard' soils purchased from LUFA Speyer in Germany and which are routinely used in soil experiments. The Welltown soil was analysed to compare fluorescein diacetate (FDA) measurements on a soil that had been stored in the dark at room temperature for 2 years (the LUFA soils) to a fresh soil sourced from Welltown near Kingston, Cornwall in July 2016 (named 'Welltown' soil here). All soils were air-dried and sieved to $<2 \mathrm{~mm}$ prior to use. OECD 106 test guidance provides physico-chemical ranges for up to 7 soils, with $\mathrm{pH}$ ranging from $<4.5$ to $>7.5$, organic carbon content $<0.5$ to $>10 \%$ and clay content from $<10$ to $80 \%$. The soils selected for this study provided a wide range of physico-chemical parameters; $\mathrm{pH}$ ranged across $3 \mathrm{pH}$ units from acidic to basic, organic carbon content ranged between the lowest to the second highest of the 7 recommended soils and clay content was between 2.9 and $26 \%$, encompassing 5 of the 7 OECD 106 soils. These soils were therefore considered to cover the range of key physico-chemical properties likely to play a key role in controlling the fate of APIs in soil. 
Table 1 Properties of the selected soils (sandy loam and loam are mean values of different batch analyses \pm S.D. (LUFA Speyer, 2015))

\begin{tabular}{llll}
\hline & Sandy loam & Loam & Welltown \\
\hline pH (10 $\left.\mathbf{~ m M ~ C a C l}_{2}\right)$ & $5.7 \pm 0.6$ & $7.3 \pm 0.1$ & 4.4 \\
Organic carbon (\%) & $0.67 \pm 0.03$ & $2.03 \pm 0.22$ & 4.94 \\
Clay content (\%) & $6.3 \pm 1.9$ & $26.0 \pm 1.9$ & $2.85 \pm 0.09$ \\
Silt content (\%) & $33.8 \pm 0.2$ & $41.0 \pm 1.4$ & $73.0 \pm 1.22$ \\
Sand content (\%) & $59.9 \pm 1.9$ & $33.0 \pm 2.0$ & $24.2 \pm 1.30$ \\
$\begin{array}{l}\text { Cation exchange } \\
\left.\text { capacity (MEQ 100 } \mathbf{~ g}^{-1}\right)\end{array}$ & $7.5 \pm 0.9$ & $33.0 \pm 4.5$ & 27.8 \\
\hline
\end{tabular}

\subsection{Sterilisation methods}

Three commonly reported sterilisation methods were compared in this study:

112 autoclaving, gamma irradiation and sodium azide.

\section{$113 \quad 2.2 .1 \quad$ Autoclaving}

Soils $(6.00 \pm 0.01 \mathrm{~g})$ were autoclaved at $126{ }^{\circ} \mathrm{C}$ for 35 minutes under vacuum in

115 polypropylene centrifuge tubes (Powlson and Jenkinson 1976). This process can be repeated

116 with a room temperature incubation (approx. 24 hour) between autoclave cycles to ensure that

117 all microbes and spores are eliminated. The 24 hour delay allows heat-resistant spores to

118 germinate and then be killed on the next autoclave cycle (Miyaki et al. 1996). However, to

119 establish the impact of autoclaving on physico-chemical characteristics of the soil, one one

120 cycle was applied in this study. 


\subsubsection{Gamma irradiation}

Soils were irradiated by BD Ltd. (Plymouth UK). Sub-samples of the soils were weighed into polyethylene sample bags (approximately 18 or $30 \mathrm{~g}$ depending on intended purpose) and double bagged. The dose applied to the soils was 25.6-26.1 kGy which has been applied in previous studies (Lensi et al. 1991; Bank et al. 2008; Buchan et al. 2012; Redshaw et al. 2008). Once the soils were returned to the laboratory they were handled aseptically under a laminar flow hood (Bassaire, class 100) to minimise contamination.

\subsubsection{Sodium azide}

Sodium azide (Aldrich Chemicals Ltd or Acros Organics, UK) was chosen as the

130 chemical inhibitor for microbial activity in soils due to its reported use in pharmaceutical fate

131 studies (Chefetz et al. 2006; Lin and Gan 2011; Vasudevan et al. 2009). The concentration of sodium azide used in soil solutions $\left(6 \mathrm{~g}\right.$ soil, $\left.30 \mathrm{~mL} 10 \mathrm{mM} \mathrm{CaCl}_{2}\right)$ was $0.2 \mathrm{~g} \mathrm{~L}^{-1}$ (equivalent of $6 \mathrm{mg}$ of sodium azide per $30 \mathrm{~mL}$ soil solution) as used previously (Lin and Gan 2011;

134 Yamamoto et al. 2009). Addition to the soil solution prior to shaking ensured full mixing.

\subsection{Sterility assessment}

Two standard methods were employed to estimate the total enzyme activity and quantify colony forming units in the soils before and after each sterilisation treatment. These methods are estimates because of the diverse nature of microbial populations in soils, meaning that not all microbial types will produce measurable effects.

\subsubsection{Fluorescein diacetate hydrolysis}

Fluorescein diacetate (FDA) is widely used to estimate total microbial activity in a

142 range of environmental samples (Adam and Duncan 2001). The method reported by Adam and

143 Duncan (2001) was followed; it was adapted to optimise sensitivity by lengthening the

144 incubation period. Colourless FDA is hydrolysed by a number of different cell-bound and free 
145 enzymes (e.g. proteases, lipases and esterases) providing a broad-spectrum indicator of soil 146 biological activity (Adam and Duncan 2001; Bandick and Dick 1999; Green et al. 2006). The 147 hydrolysis releases a yellow-coloured end product, fluorescein, which is measured by at a 148 wavelength of $490 \mathrm{~nm}$.

149 A $120 \mathrm{mM}$ phosphate buffer was prepared by dissolving $19.67 \mathrm{~g}$ sodium phosphate 150 tribasic anhydrous (AlfaAesar, UK) in $1 \mathrm{~L}$ high purity water (HPW). Sodium phosphate 151 monobasic dihydrate was added to achieve a pH of 7.6. A $60 \mathrm{mM}$ buffer solution was prepared 152 by diluting the $120 \mathrm{mM}$ buffer using HPW and adjusting the $\mathrm{pH}$ as required with sodium 153 phosphate monobasic dihydrate. Buffer solutions were stored at $4{ }^{\circ} \mathrm{C}$ for up to one week and 154 the $\mathrm{pH}$ checked before use. A pH 7.6 buffer solution was used in all FDA hydrolysis experiments because FDA has been found to reach a maximum rate of hydrolysis at this $\mathrm{pH}$ (Green et al. 2006). Maintaining the $\mathrm{pH}$ at 7.6 also reduces the risk of solubilising organic matter that can interfere with the UV-visible spectrophotometry and produce very high 158 background blanks (Adam and Duncan 2001; Swisher and Carroll 1980). The FDA solution 159 was prepared by dissolving $0.1 \mathrm{~g}$ FDA (AlfaAesar, UK) in $100 \mathrm{~mL}$ AR grade acetone (Acros 160 Organics, UK); it was stored at $4{ }^{\circ} \mathrm{C}$ for up to one week. Calibration solutions were prepared on the day of analysis using fluorescein sodium 162 salt (Sigma Aldrich, UK) in $60 \mathrm{mM}$ sodium phosphate buffer solution. Calibration graphs were 163 prepared in the concentration range of $0-10 \mathrm{mg} \mathrm{L}^{-1}$ and provided a straight line $\left(\mathrm{R}^{2}>0.999\right.$ with equation $\left(\right.$ Absorbance $=0.2015 X+0.0276$; where $X=$ fluorescein concentration in $\mathrm{mg} \mathrm{L}^{-}$ ${ }^{1}$ ) (Figure S2). Standard deviations were calculated with a maximum standard deviation of $0.023 \mathrm{AU}$ for the $10 \mathrm{mg} \mathrm{L}^{-1}$ standard (Table S1). 
2.3.2 The method outlined by Adam (2001) and Schofield (2015) was followed with the incubation time extended to maximise fluorescein production and make analytical measurements more robust by improving the limit of detection and reduce RSD to less than $10 \%$. Soil $(2.00 \pm 0.01 \mathrm{~g})$ was accurately weighed into sterile $50 \mathrm{~mL}$ polypropylene centrifuge tubes and $15 \mathrm{~mL} 60 \mathrm{mM}$ sodium phosphate buffer (pH 7.6) added. A $200 \mu \mathrm{L}$ aliquot of FDA (1000 $\mu \mathrm{g}$ FDA $\left.\mathrm{mL}^{-1}\right)$ solution was added and the tubes mixed by inversion. The tubes were incubated in a water bath at $30{ }^{\circ} \mathrm{C}$ for 3 hours, then centrifuged $(2000$ RPM, 5 minutes) and immediately analysed at 490 nm on a Hewlett-Packard 3454 UVVIS spectrophotometer. No termination step was used as this can reduce the fluorescein signal (Adam and Duncan 2001; Schumacher et al. 2015). As a result, incubations were staggered to allow for immediate analysis once the incubation period was complete. Estimation of colony forming units

Colony forming units were estimated using the standard method outlined in Eaton et al. (1995). A representative soil slurry was decanted from tubes containing $1: 5$ soil : $10 \mathrm{mM}$ $\mathrm{CaCl}_{2}$ solutions, into sterile containers under a laminar flow hood. A single $100 \mu \mathrm{L}$ aliquot of a 1 : 10 dilution (using HPW) was spread across the surface of a tryptone glucose yeast agar plate. Plates were incubated at $30{ }^{\circ} \mathrm{C}$ for 72 hours and colony forming units were counted.

Plating was used for soils containing sodium azide as the azide interfered with the FDA measurement. This was shown by adding $0.2 \mathrm{~g} \mathrm{~L}^{-1}$ of sodium azide to HPW and comparing FDA results with HPW only. HPW containing sodium azide had measured fluorescein concentrations three times higher than in HPW alone (2.49 and $0.8 \mathrm{mg} \mathrm{L}^{-1}$, respectively).

\subsubsection{DOC}

DOC was measured by high temperature catalytic combustion using a Shimadzu TOCV analyser after Badr et al (2003). Prior to analysis, filtered samples $(0.7 \mu \mathrm{m}$ ashed glass fibre 
191 filters) were acidified to ca. $\mathrm{pH} 2$ using $6 \mathrm{M}$ AR grade $\mathrm{HCl}$. HPW, acidified to ca. $\mathrm{pH}$ 2, was

192 used if samples required dilution. DOC standards were prepared using potassium hydrogen 193 phthalate in a concentration range of $0-677 \mu \mathrm{M} \mathrm{C}$.

$194 \quad 2.3 .4 \quad \mathbf{p H}$

195 Soil $(10.00 \pm 0.01 \mathrm{~g})$ and $25 \mathrm{~mL} 10 \mathrm{mM} \mathrm{CaCl}_{2}$ were transferred to polypropylene 196 centrifuge tubes (50 mL; Fisher Scientific UK) in triplicate. Tubes were shaken for 15 minutes

197 before $\mathrm{pH}$ was measured using a HANNA HI 9025 microcomputer $\mathrm{pH}$ meter fitted with a 198 Camlab epoxy tough single junction combination pH electrode (Rowell 1994). This was 199 calibrated daily before use with buffers at $\mathrm{pH} 4.01$ and 7.00 (Thermo Scientific). 


\section{Results}

\subsection{Fluorescein method performance}

Matrix blanks were determined using $200 \mu \mathrm{L}$ of AR grade acetone used instead of FDA.

203 These absorbance values were subtracted from sample data to account for matrix effects (Table

204 2).

Table 2 FDA results for soil samples and blanks

\begin{tabular}{|c|c|c|}
\hline Soil & Sample $\left(\mu g g^{-1} L^{-1}\right)^{*}$ & Blank $\left(\mu g^{-1} L^{-1}\right)^{*}$ \\
\hline Loam & $26.9 \pm 0.8$ & $3.94 \pm 0.01$ \\
\hline Irradiated loam & $24.7 \pm 0.7$ & $4.39 \pm 0.00$ \\
\hline Sandy loam & $12.8 \pm 0.1$ & $0.70 \pm 0.04$ \\
\hline Irradiated sandy loam & $9.75 \pm 0.27$ & $0.64 \pm 0.10$ \\
\hline Welltown soil & $28.5 \pm 3.8$ & $6.16 \pm 0.01$ \\
\hline
\end{tabular}

*data as $\overline{\mathrm{x}} \pm$ S.D. $\mathrm{n}=9$ or 6 for samples (blank not subtracted) and 3 for blanks

The instrumental LOD was estimated to be $0.4 \mathrm{mg} \mathrm{L}^{-1}$ based on calculations using blank

+3 times the standard deviation of the blank; all sample concentrations were above this value before converting to fluorescein production rate to take into account the incubation time.

\subsection{Autoclaving}

Autoclaving changed the soil structure and visibly altered it to a powder, significantly

212 increasing the surface area available for sorption of APIs. Measurement of the DOC

213 concentrations in soil : water (1:5) showed that the concentration had increased after

214 autoclaving. The concentration of DOC in the loam soil increased from $3.3 \mathrm{mM}$ to

215 approximately $10.8 \mathrm{mM}$ (43 to $130 \mathrm{mg} \mathrm{L}^{-1}$ respectively) and the sandy loam soil increased from

2165 to $44 \mathrm{mg} \mathrm{L}^{-1}$. As such, this method was not appropriate for sorption experiments, as the soils 
217 could not be compared with non-sterile soils. Consequently, the sterility of the autoclaved soils

218 was not measured.

\subsubsection{Gamma irradiation}

Gamma irradiation did not successfully sterilise the loam and sandy loam soils (Figure

1). A small but statistically significant decrease in the total soil enzyme activity was measured in both soils after gamma irradiation (unpaired t-test, unequal variances, two-tailed, $p \leq 0.01$ ).

223 The Welltown soil was tested as it had not been stored for a long period of time (2 months),

224 unlike the loam and sandy loam soils, so that the total enzyme activity should not have been

225 affected. Total enzyme activity in the fresh Welltown soil was not significantly different to the 226 loam soil, which had been stored for 2 years (unpaired t-test, unequal variances, two-tailed, $227 \mathrm{p}=0.01)$.

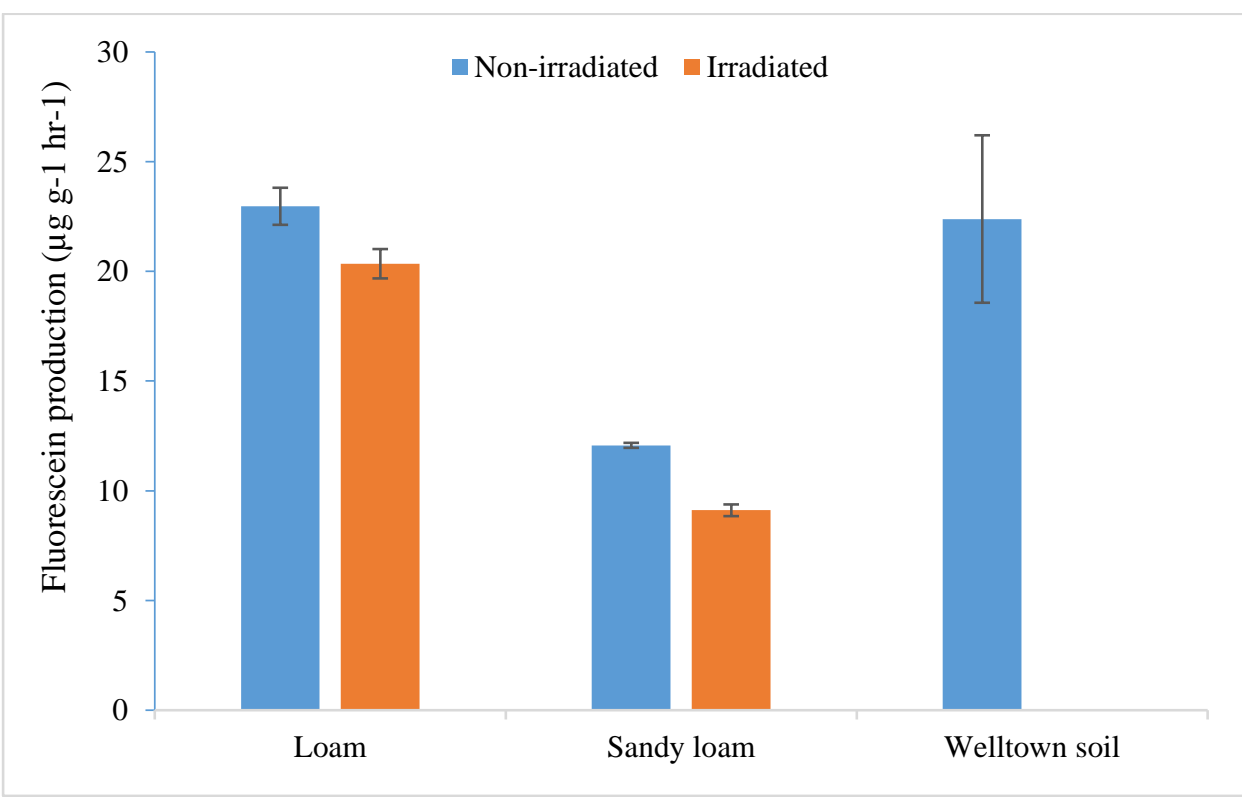

Figure 1 Fluorescein production in irradiated and non-irradiated soils (presented as $\overline{\mathbf{x}} \pm$ S.D.; $n=6$ or 9 ) 


\subsubsection{Sodium azide}

Colony forming units were counted after incubation on tryptone glucose yeast agar

234 plates. Sandy loam soil had numerous swarming colonies which hampered quantification of numbers; however, diversity was similar across untreated and treated soils and across all time points. Loam samples had different diversity depending on the treatment; untreated loam soils contained swarming filamentous species (probably Bacillus spp.) whereas the treated soil did not, but had a number of colourful isolates instead. Overall, no microbial inhibition was observed after the addition of $0.2 \mathrm{~g} \mathrm{~L}^{-1}$ sodium azide to the two LUFA soils.

\subsection{3 pH}

An increase in soil solution $\mathrm{pH}$ occurred in the loam soil $(0.53 \mathrm{pH}$ units $)$ after the addition of $0.2 \mathrm{~g} \mathrm{~L}^{-1}$ sodium azide (Table 3). No other treatments in the loam soil produced significant differences compared to an unaltered 'normal' sample. Sandy loam soil had a decrease in $\mathrm{pH}$, after all treatments, of approximately $0.3 \mathrm{pH}$ units.

Table 3 pH of soil solutions ( $10 \mathrm{mM} \mathrm{CaCl}$ ) after sterilisation.

\begin{tabular}{lll}
\hline & Loam* & Sandy loam* \\
\hline Untreated & $6.36 \pm 0.05$ & $5.83 \pm 0.05$ \\
Autoclaved & $6.44 \pm 0.04$ & $5.55 \pm 0.01$ \\
Gamma irradiated & $6.38 \pm 0.11$ & $5.53 \pm 0.02$ \\
Sodium azide & $6.93 \pm 0.02$ & $5.54 \pm 0.01$ \\
\hline
\end{tabular}

*Data presented as $\overline{\mathrm{x}} \pm$ S.D. $(\mathrm{n}=3)$

2474 Discussion many environmental factors, including soil moisture, aeration, land use, $\mathrm{pH}$, temperature, 
organic matter and nutrient levels (van Elsas et al. 2006). Variations in microbial populations may lead to different biodegradation rates for chemicals between soil types. This poses challenges for environmental risk assessments as separating biodegradation from sorption is vital for a risk assessment to be carried out. Thorough sterilisation of soils to be used in methods such as OECD 106 is needed to ensure that the specific biogeochemical processes can be investigated. To distinguish these two processes a sorption profile in sterile, or microbialactivity supressed, and natural soil needs to be performed, so that the physico-chemical structure of the soil is maintained after sterilisation.

Autoclaving is the most common sterilisation method for soils, due to the ease of access to an autoclave in many laboratories (Trevors 1996; Berns et al. 2008), and has been used in OECD 106-related research (Xu et al. 2009; Estevez et al. 2014; Mrozik and Stefańska 2014; Zhang et al. 2013). Furthermore repeated cycles ( 2 or 3 times) of autoclaving has been shown to be effective in sterilising soils (Wolf et al., 1989). However, in the current study a single cycle of autoclaving converted the soil to a powder form and greatly increased the surface area available for sorption; which has been reported (Trevors 1996; Berns et al. 2008). Berns et al. (2008) also observed a 29 to 37 -fold increase in the DOC content of soil solutions after autoclaving two soils, while large increases in DOC have been measured after autoclaving in other studies (Powlson and Jenkinson 1976; Shaw et al. 1999). Organic carbon physically trapped between particles may have been solubilised while autoclaving may also detach organic carbon from particle surfaces (Powlson and Jenkinson 1976; Berns et al. 2008). In contrast, Lotrario et al. (1995) measured a decrease in soil surface area (55\%) after one dry cycle (30 minutes at $121^{\circ} \mathrm{C}$ ) in the autoclave, suggesting that soil pores may have collapsed causing aggregation of clay particles, resulting in a greater proportion of larger particles. A smaller decrease (40\%) in surface area was measured by Wolf et al (1989) after 2-3 cycles of autoclaving, which was attributed to the smoothing of irregular shaped particles and allowing 
275 clumping to take place. Differences in surface area after autoclaving could be attributed to 276 different analytical methods of determining the aggregation of soil, such as mechanical or 277 gentle aggregate fractionation (Berns et al. 2008). Autoclaving also decreases soil pH, 278 attributed to the release of organic acids from the soil organic matter, but other studies observed no pH difference (Wolf et al. 1989; Shaw et al. 1999; Berns et al. 2008). Both of these outcomes 280 were apparent in this study; the loam soil $\mathrm{pH}$ did not change whereas sandy loam showed a decrease of $0.3 \mathrm{pH}$ units (Table 3). Changes in the physical structure of the soils observed in this and other studies indicate that autoclaving of soils will have an impact on the sorption profiles of APIs in soils, as increasing the surface area will increase available sorption sites. Furthermore, increasing DOC concentrations in sorption experiments in the aqueous phase can decrease the sorption of analytes owing to complexation in the dissolved phase, potentially leading to inaccurate risk assessments that do not reflect environmental conditions (Carmosini and Lee 2009; Day 1991). Impacts on soil thus appear to vary with different soils so individual assessments should be carried out when using autoclaving as a sterilisation method.

A small, but statistically significant, change in total enzyme activity was measured after gamma irradiation of the soils, potentially because the amount of radiation used was too low (25 kGy), although this level of radiation has been successful in several studies (Lensi et al. 1991; Bank et al. 2008; Buchan et al. 2012). Others have suggested that a higher radiation dose is required to achieve sterilisation (up to $70 \mathrm{kGy}$ ) (McNamara et al. 2003; Kahle and Stamm 2007). However, higher doses have been reported to affect soil physico-chemical properties, such as variations in soluble carbon, exchangeable cation concentrations, $\mathrm{pH}$ and clay mineral chemistry (Lensi et al. 1991). Even at $25 \mathrm{kGy}$ gamma irradiation has been reported to produce a 1.7 to 3.3 fold increase in DOC concentrations (Lensi et al. 1991). Smaller increases in DOC concentrations were measured in soils irradiated at $35 \mathrm{kGy}$, where only $2 \%$ of total organic carbon was released into solution (Berns et al. 2008). It was hypothesized that increases in 
300 DOC after irradiation was probably due to lysis of cells and degradation of soil organic matter 301 (Lensi et al. 1991).

Although changes in DOC concentrations with gamma irradiation have been reported,

303 there is little evidence to suggest that gamma irradiation affects soil structure (Lensi et al.

304 1991). There are no consistent trends apparent in studies reporting effects of irradiation on $\mathrm{pH}$; however, it has been suggested that the moisture content of soil at the time of irradiation may change soil pH (Lotrario et al. 1995; McNamara et al. 2003). CEC decreased in soils after irradiation (at $20 \mathrm{kGy}$ ) from 39 to $31 \mathrm{cmol}_{\mathrm{c}} \mathrm{kg}^{-1}$ and was attributed to the breakdown of natural organic matter (Bank et al. 2008). Changes in CEC will impact the sorption of ionisable compounds to soil depending on the charge on the compound and whether there is an increase or decrease in CEC. Decreases in CEC will reduce sorption of cations due to a removal of

311 potential sorption sites. Studies have reported that all studied sterilisation methods (irradiation, autoclaving and sodium azide) had no significant effect on CEC (Wolf et al. 1989; Lotrario et al. 1995). The reported variation with regards to changes in soil texture and chemistry after gamma irradiation suggests that, while this may be the best available method of soil sterilisation for sorption studies, different soils and the doses of gamma irradiation used will affect results. When irradiation is used, controls must be in place to limit changes to soils so that sterilised soils can be compared with untreated soils; for example, by comparing soil physico-chemical 318 properties before and after irradiation. From a practicality point of view, gamma irradiation is usually carried out at specialised facilities which increases costs and may lead to delays in testing.

Sodium azide did not inhibit microbial activity at the concentration used in this experiment. This concentration $\left(0.2 \mathrm{~g} \mathrm{~L}^{-1}\right)$ has been used in sorption experiments as a biocide to minimise or suppress microbial activity (Yamamoto et al. 2009; Lin and Gan 2011). Higher concentrations of sodium azide have also been used, ranging from 0.5 to $0.98 \mathrm{~g} \mathrm{~L}^{-1}$ (ter Laak 
et al. 2006; Vasudevan et al. 2009; Zhang et al. 2013). The lower end of reported concentrations was used in the present study as sodium azide has the potential to interfere with soil chemical properties (Trevors 1996). Soil solution $\mathrm{pH}$ increased slightly after the addition of sodium azide to the loam soil (Table 3). A more significant $\mathrm{pH}$ change, from 5.2 to 8.7 after 30 days incubation with $5 \%$ sodium azide compared with control samples where no change occurred,

330 has been reported (Rozycki and Bartha 1981). Variation of $\mathrm{pH}$ will be a function of the soil buffering capacity (Trevors 1996). This could potentially influence the ionisation state of APIs or other chemicals that are in ionic form at environmental $\mathrm{pH}$. Sodium azide is low cost and easy to access but it is toxic so must be handled and disposed of with care.

The FDA method used was a well-established test for bacterial microbial activity within the soil. A preliminary experiment was necessary to compare the activity of the aged LUFA soils with that of a recently collected 'fresh' soil in order to establish if storage of soil could impact on its microbial activity. The data from the FDA experiments was compared with data reported for non-irradiated soils (Table 4). Total enzyme activity from the FDA experiment in the sandy loam soil was lower than reported values, which may have resulted from the long storage period. The loam and Welltown soils had similar total enzyme activity to the lowest reported data values (Table 4). Air drying soils reduces the concentration of adenosine 5'triphosphate (ATP), which is used as a measure of microbial biomass in soil. Storing soils

343 decreases the ability of microbial biomass to restore the ATP concentration after rewetting

344 (Mondini et al. 2002; De Nobili et al. 2006). For example a soil (from stubbed grassland) stored for 2 years had ATP concentrations which were only $14 \%$ of that of the fresh soil after rewetting (De Nobili et al. 2006). Some soil microorganisms have developed capabilities for surviving in dry conditions for long periods, including the production of endospores, cysts or conidia, which may explain why some microbial activity can be recorded after periods of storage (Chen and Alexander 1973). The levels of organic matter probably have an impact on 
350 the survival of bacteria where soils with higher levels of organic matter 'protect' 351 microorganisms by reducing oxidative radical reactions (De Nobili et al. 2006). This is shown 352 in Table 4 where the loam and Welltown soils had the highest enzyme activity and high organic 353 carbon levels (Table 1). 
356 Table 4. Comparison of experimental total enzyme activity data to literature values with associated soil properties

\begin{tabular}{|c|c|c|c|c|c|}
\hline Land use/soil type & pH & $\begin{array}{l}\text { Organic } \\
\text { carbon }(\%)\end{array}$ & $\begin{array}{l}\text { Cation exchange } \\
\text { capacity (MEQ } \\
\left.100 \mathrm{~g}^{-1}\right)\end{array}$ & $\begin{array}{l}\text { Fluorescein } \\
\text { production } \\
\left(\mu \mathrm{g} \mathrm{g}^{-1} \mathbf{h r}^{-1}\right)\end{array}$ & Reference \\
\hline Loam & $7.3 \pm 0.1$ & $2.03 \pm 0.22$ & $33.0 \pm 4.5$ & $23.0 \pm 0.1$ & This study \\
\hline Irradiated loam & & & & $20.3 \pm 0.1$ & This study \\
\hline Sandy loam & $5.7 \pm 0.6$ & $0.67 \pm 0.03$ & $7.5 \pm 0.9$ & $12.1 \pm 0.01$ & This study \\
\hline $\begin{array}{l}\text { Irradiated sandy } \\
\text { loam }\end{array}$ & $5.7 \pm 0.6$ & & & $9.1 \pm 0.04$ & This study \\
\hline Welltown soil & 4.4 & 4.94 & 27.8 & $22.4 \pm 0.5$ & This study \\
\hline $\begin{array}{l}\text { Crop land silty clay } \\
\text { loam }\end{array}$ & & & & $\sim 60$ & $\begin{array}{l}\text { (Schumacher } \\
\text { et al. 2015) }\end{array}$ \\
\hline Crop land loam & & & & $\sim 28$ & $\begin{array}{l}\text { (Schumacher } \\
\text { et al. 2015) }\end{array}$ \\
\hline $\begin{array}{l}\text { Crop land } \\
\text { loam }\end{array}$ & & & & $\sim 40$ & $\begin{array}{l}\text { (Schumacher } \\
\text { et al. 2015) }\end{array}$ \\
\hline $\begin{array}{l}\text { Grassland sandy } \\
\text { loam }\end{array}$ & & & & $\sim 22$ & $\begin{array}{l}\text { (Schumacher } \\
\text { et al. 2015) }\end{array}$ \\
\hline $\begin{array}{l}\text { Crop land sandy } \\
\text { loam }\end{array}$ & & & & 40 & $\begin{array}{l}\text { (Debosz et al. } \\
2002 \text { ) }\end{array}$ \\
\hline
\end{tabular}


Data presented here compares, for the first time, sterilisation methodologies applied to

362 the OECD 106 adsorption-desorption batch equilibrium test method. Although previous studies

363 have reported on the efficacy of sterilisation methods for soils, none have compared available

364 methods applied to the specific conditions used in the OECD 106 test, now commonly used in

365 the risk assessment of chemicals within the soil environment. The data showed that none of the samples in this study was successfully sterilised; as a consequence, the this would represent a failure to follow the recommended OECD 106 method i.e. use of sterile soils to facilitate the complete separation of sorption processes from biodegradation. As reported sterilisation methods were tested in this study, our findings have significant implications for future research. Specific methods are often applied with the assumption that the method delivers 'sterilised' soils. The work presented here shows that this a questionable assumption, and that some form of testing of the 'activity' of the soil should be undertaken to confirm the absence or levels of enzyme or other activity. Consequently, sterilisation techniques may be soil-specific and should be thoroughly tested prior to undertaking abiotic sorption experiments for environmental risk assessments.

All of the methods presented here can influence soil physico-chemical properties; this could lead to incomparable sterile sorption profiles making the data less robust, potentially

378 leading to inaccurate assumptions regarding the fate and behaviour of chemicals in the soil environment, particularly those which are influenced by particle size, $\mathrm{pH}$ and organic carbon concentration changes (i.e. APIs and some pesticides). Recommendations on the sterilisation of soils and how to minimise physico-chemical disturbance for sorption-desorption batch experiments should be included within the test guidelines documentation. The difficulty with 
this recommendation is that the soils appear to act differently according to sterilisation conditions.

Having compared three widely-used sterilisation approaches in this study, it appears that gamma irradiation is most appropriate for the OECD 106 method as it has the lowest impact on the soil structure, though care needs to be taken to ensure that sterilisation is achieved or recognise that some removal may be biologically mediated.

Acknowledgement - The authors acknowledge Dr Matt Emery, from the School of Biology, Plymouth University for his assistance in measuring colony forming units. The AstraZeneca Global SHE Research Programme is thanked for funding this research.

\section{References}

Adam, G. and Duncan H., 2001. Development of a sensitive and rapid method for the measurement of total microbial activity using fluorescein diacetate (FDA) in a range of soils. Soil Biol Biochem. 33, 943-951.

Al-Rajab, A. J., Sabourin L., Lapen D.R. and Topp E., 2010. The non-steroidal antiinflammatory drug diclofenac is readily biodegradable in agricultural soils. Sci Total Environ. $409,78-82$

400 Bandick, A. K. and Dick R.P., 1999. Field management effects on soil enzyme activities. Soil 401 Biol Biochem. 31, 1471-1479.

402 Bank, T. L., Kukkadapu R.K., Madden A.S., Ginder-Vogel M.A., Baldwin M.E. and Jardine 403 P.M., 2008. Effects of gamma-sterilization on the physico-chemical properties of natural sediments. Chem Geol. 251, 1-7.

405 Berns, A. E., Philipp H., Narres H.D., Burauel P., Vereecken H. and Tappe W., 2008. Effect 406 of gamma-sterilization and autoclaving on soil organic matter structure as studied by solid state 407 NMR, UV and fluorescence spectroscopy. Eur J Soil Sci. 59, 540-550.

408 Buchan, D., Moeskops B., Ameloot N., De Neve S. and Sleutel S., 2012. Selective sterilisation 409 of undisturbed soil cores by gamma irradiation: Effects on free-living nematodes, microbial 410 community and nitrogen dynamics. Soil Biol and Biochem. 47, 10-13.

411 Carmosini, N. and Lee L.S., 2009. Ciprofloxacin sorption by dissolved organic carbon from 412 reference and bio-waste materials. Chemosphere 77: 813-820. 
413 Chefetz, B., Stimler K., Shechter M. and Drori Y., 2006. Interactions of sodium azide with 414 triazine herbicides: Effect on sorption to soils. Chemosphere 65: 352-357.

415 Chen, M. and Alexander M., 1973. Survival of soil bacteria during prolonged desiccation. Soil 416 Biol and Biochem. 5, 213-221.

417 Day, K. E., 1991. Effects of dissolved organic carbon on accumulation and acute toxicity of 418 fenvalerate, deltamethrin and cyhalothrin to Daphnia magna (straus). Environ Toxicol Chem. 419 10, 91-101.

420 De Nobili, M., Contin M. and Brookes P.C., 2006. Microbial biomass dynamics in recently air421 dried and rewetted soils compared to others stored air-dry for up to 103 years. Soil Biol 422 Biochem. 38, 2871-2881.

423 Debosz, K., Petersen S.O., Kure L.K. and Ambus P., 2002. Evaluating effects of sewage sludge 424 and household compost on soil physical, chemical and microbiological properties. Appl Soil 425 Ecol. 19, 237-248.

426 Eaton, A. D., Clesceri L.S., Greenberg A.E.. American Public Health, F. Water Environment 427 and A. American Water Works (1995). Standard methods for the examination of water and 428 wastewater, American Public Health Asssociation.

429 ECETOC, 2013. Environmental Exposure Assessment Of Ionisable Organic Compounds, 430 Technical Report 123. Brussels, ECETOC.

431 Estevez, E., Hernandez-Moreno J.M., Fernandez-Vera J.R. and Palacios-Diaz M.P., 2014. 432 Ibuprofen adsorption in four agricultural volcanic soils. Sci Total Environ, Supplement C, 406433414.

434 Green, V. S., Stott D.E. and Diack M., 2006. Assay for fluorescein diacetate hydrolytic activity: 435 Optimization for soil samples. Soil Biol Biochem. 38, 693-701.

436 Jornitz M.W. \& Meltzer, T.H., 2000. Identifying the sterilizing filter. Pharm Technol. 24, 3843746.

438 Kahle, M. and Stamm C., 2007. Time and pH-dependent sorption of the veterinary 439 antimicrobial sulfathiazole to clay minerals and ferrihydrite. Chemosphere 68, 1224-1231.

440 Lees, K., Fitzsimons M., Snape J., Tappin A. and Comber S., 2016. Pharmaceuticals in soils 441 of lower income countries: Physico-chemical fate and risks from wastewater irrigation. 442 Environ Int. 94, 712-723. 
443 Luef, B , Frischkorn, K.R., Wrighton, K.C., Holman, H-Y.N., Birarda, G., Thomas, B.C, Singh, 444 A., Williams, K.H., Siegerist, C.E., Tringe, S.G., Downing, K.H., Comolli, L.R., Banfield, J.F., 445 2015. Diverse uncultivated ultra-small bacterial cells in groundwater. Nat Commun. 6, 63724466382.

447 Lensi, R., Lescure C., Steinberg C., Savoie J.M. and Faurie G., 1991. Dynamics of residual 448 enzyme activities, denitrification potential, and physico-chemical properties in a $\gamma$-sterilized 449 soil. Soil Biol Biochem. 23, 367-373.

450 Lin, K. and Gan J., 2011. Sorption and degradation of wastewater-associated non-steroidal 451 anti-inflammatory drugs and antibiotics in soils. Chemosphere, 83, 240-246.

452 Lotrario, J. B., Stuart B.J., Lam T., Arands R.R., O'Connor O.A. and Kosson D.S., 1995. 453 Effects of sterilization methods on the physical characteristics of soil: Implications for sorption 454 isotherm analyses. B Environ Contam Tox.54, 668-675.

455 McNamara, N. P., Black H.I.J., Beresford N.A. and Parekh N.R., 2003. Effects of acute gamma 456 irradiation on chemical, physical and biological properties of soils. App Soil Ecol. 24, 117457132.

458 Miyaki, T., Oyaizu H. and Matsumoto S., 1996. Methanogenesis from Dried and Heat Treated 459 Paddy Soil. Microbes Environ. 11, 51-55.

460 Mondini, C., Contin M., Leita L. and De Nobili M., 2002. Response of microbial biomass to 461 air-drying and rewetting in soils and compost. Geoderma, 105, 111-124.

462 Mrozik, W. and Stefańska J., 2014. Adsorption and biodegradation of antidiabetic 463 pharmaceuticals in soils. Chemosphere. 95, 281-288.

464 OECD (2000). Test No. 106: Adsorption -- Desorption Using a Batch Equilibrium Method. 465 Paris, OECD Publishing.

466 Oxford University Press (2002). Oxford English Dictionary Online. Oxford, England, Oxford 467 University Press.

468 Powlson, D. S. and Jenkinson D.S., 1976. The effects of biocidal treatments on metabolism in 469 soil-II. Gamma irradiation, autoclaving, air-drying and fumigation. Soil Biol Biochem. 8, $470 \quad 179-188$. 

of fluoxetine $\mathrm{HCl}$, diazepam and their human metabolites in sewage sludge-amended soil. $\mathbf{J}$ Soils Sed. 8, 217-230.

474 Rowell, D. L., 1994. Soil Methods and Applications. Harlow, Addison Welsey, Longman 475 Limited.

476 Rozycki, M. and Bartha R., 1981. Problems associated with the use of azide as an inhibitor of 477 microbial activity in soil. Appl Environ Microbiol. 41, 833-836.

478 Schumacher, T. E., Eynard A. and Chintala R., 2015. Rapid cost-effective analysis of microbial 479 activity in soils using modified fluorescein diacetate method. Environ Science Poll Res. 22, $480 \quad 4759-4762$.

481 Shaw, L. J., Beaton Y., Glover L.A., Killham K. and Meharg A.A., 1999. Re-inoculation of 482 autoclaved soil as a non-sterile treatment for xenobiotic sorption and biodegradation studies. App Soil Ecol. 11, 217-226.

Skipper H.D. and Westermann D.T. (1973) Comparative effects of propylene oxide, sodium azide, and autoclaving on selected soil properties. Soil Biol Biochem. 5, 409-414.

486 Swisher, R. and Carroll G.C., 1980. Fluorescein diacetate hydrolysis as an estimator of 487 microbial biomass on coniferous needle surfaces. Micro Ecol. 6, 217-226.

488 ter Laak, T. L., Gebbink W.A. and Tolls J., 2006. The effect of pH and ionic strength on the 489 sorption of sulfachloropyridazine, tylosin, and oxytetracycline to soil. Environ Tox Chem. 25, $490 \quad 904-911$.

491 Trevors, J. T. (1996). Sterilization and inhibition of microbial activity in soil. J Microbiol Meth. 492 26, 53-59.

493 van Elsas, J. D., Trevors J.T., Jansson J.K. and Nannipieri P., 2006. Modern Soil Microbiology, 494 CRC press.

495 Vasudevan, D., Bruland G.L., Torrance B.S., Upchurch V.G. and MacKay A.A., 2009. pH496 dependent ciprofloxacin sorption to soils: Interaction mechanisms and soil factors influencing 497 sorption. Geoderma 151, 68-76.

498 Wolf, D. C., Dao T.H., Scott H.D. and Lavy T.L., 1989. Influence of Sterilization Methods on 499 Selected Soil Microbiological, Physical, and Chemical Properties. J Environ Qual. 18, 39-44. 
$500 \mathrm{Xu}, \mathrm{J} ., \mathrm{Wu}$ L. and Chang A.C., 2009. Degradation and adsorption of selected pharmaceuticals

501 and personal care products (PPCPs) in agricultural soils. Chemosphere. 77, 1299-1305.

502 Yamamoto, H., Nakamura Y., Moriguchi S., Nakamura Y., Honda Y., Tamura I., Hirata Y., 503 Hayashi A. and Sekizawa J., 2009) Persistence and partitioning of eight selected 504 pharmaceuticals in the aquatic environment: Laboratory photolysis, biodegradation, and 505 sorption experiments. Wat Res. 43, 351-362.

506 Zhang, T., Wu B., Sun N., Ye Y. and Chen H., 2013. Sorption and degradation of wastewater507 associated pharmaceuticals and personal care products in agricultural soils and sediment. Wat 508 Sci Technol. 68, 991-998. 